\title{
Analytical Method Development and Validation of Bendamustine in Bulk Using RP-HPLC
}

\section{Bhawani S*, Nageshwari HG, Mamatha G, Venu M, Sai Krishna M and Murali Krishna KS}

Department of analysis, MLR institute of pharmacy, India

*Corresponding author: Sunkara Bhawani, Department of analysis, MLR institute of pharmacy, Dundigal, Quthubullapur Mandal, Hyderabad 500043, RR Dist, Telangana, Email: banu.sunkara@gmail.com

\section{Research Article}

Volume 2 Issue 2

Received Date: May 31, 2018

Published Date: August 01, 2018

\section{Abstract}

A simple, sensitive, precise, accurate and economical method was developed and validated for the estimation of Bendamustine in bulk or formulation by RP-HPLC method using Inertsil column ODS of dimensions ODS -2, (150 x 4.6) $\mathrm{mm}, 5 \mu \mathrm{m}$. The mobile phase (trifluoroacetic acid and acetonitrile ) was pumped at a flow rate of $1.5 \mathrm{ml} / \mathrm{min}$ in the ratio of $68: 32$ and the eluents were monitored at $230 \mathrm{~nm}$. Linearity was obtained in the concentration range of $10 \%-150 \%$ with $\mathrm{R}^{2}$ 0.999. LOD and LOQ were found to be $2.9 \mu \mathrm{g} / \mathrm{ml}$ and $8.75 \mu \mathrm{g} / \mathrm{ml}$. The method was statistically validated according to ICH guidelines. RSD was found to be less than $2 \%$ indicating high degree of accuracy and precision of the proposed HPLC method. The percentage recovery was in good agreement with the labeled amount in the pharmaceutical formulations.

Keywords: Treanda; HPLC; Trifluoroacetic acid

\section{Introduction}

Bendamustine bearing the name Treanda is a chemotherapic medication used in the treatment of chronic lymphocytic leukemia, multiple myeloma, and non-hodgkins lymphoma. Bendamustine is a white, watersoluble microcrystalline powder with amphoteric properties. It acts as an alkylating agent causing intra-strand and inter-strand cross-links between DNA bases. After intravenous infusion it is extensively metabolised in the liver by cytochrome $\mathrm{p} 450$. More than $95 \%$ of the drug is bound to protein primarily albumin. Only free bendamustine is active. Elimination is biphasic with a half-life of 6-10 minutes and a terminal half-life of approximately 30 minutes. It is eliminated primarily through the kidneys. Combination therapy with bendamustine and rituximab has demonstrated superior efficacy to a standard rituximabcontaining chemotherapy regimen in patients with previously untreated indolent B-cell non-Hodgkin lymphoma, and it is currently being compared against the standard first-line regimen in CLL: fludarabine, cyclophosphamide, and rituximab. Ongoing and planned studies are evaluating new strategies in which bendamustine is being combined with existing agents and with novel therapies to optimize use in different clinical settings [1-15]. 


\section{Open Access Journal of Pharmaceutical Research}

\section{Materials and Methods}

\begin{tabular}{|c|c|}
\hline Instrument name & Manufacturer \\
\hline HPLC & $\begin{array}{c}\text { Shimadzu LC 20 10 CHT pump, } \\
\text { PDA Detector }\end{array}$ \\
\hline Column & $\begin{array}{c}\text { Inertsil ODS }-2,(150 \times 4.6) \mathrm{mm}, \\
5 \mu \mathrm{m}\end{array}$ \\
\hline UV spectrophotometer & $\begin{array}{c}\text { Shimadzu, Thermo electron } \\
\text { corporation }\end{array}$ \\
\hline Electronic balance & Sartorious \\
\hline Ultra sonicator & Spectral lab-model UCB50 \\
\hline $\begin{array}{c}\text { Pipettes, burettes, } \\
\text { beakers }\end{array}$ & Borosil, class-B \\
\hline
\end{tabular}

Table 1: Instruments used in the present work.

\begin{tabular}{|c|c|}
\hline Chemicals & Manufacturer \\
\hline Bendamustine & Hetero laboratories \\
\hline Acetonitrile & Merck, Hyderabad \\
\hline Trifluoroacetic acid & Startech labs, Hyderabad \\
\hline
\end{tabular}

Table 2: Chemicals and Reagents used in the present work.

\section{Method Development and Validation of Bendamustine}

\section{Selection of Wavelength for Detection}

Selection of solvent: The solubility of bendamustine was determined in a variety of solvents as per Pharmacopoeial standards. Solubility test was carried out in different solvents like distilled water, methanol, acetonitrile, dilute ethanol. From the solubility studies, it was found that bendamustine was soluble in methanol. Methanol was selected as suitable solvent as there will be no solvent interference while scanning in UV.

Determination of wave length Maxima: UV spectrum of bendamustine in diluent (mobile phase composition) was recorded by scanning in the range of $200 \mathrm{~nm}$ to $400 \mathrm{~nm}$. From the UV spectrum wavelength selected as $230 \mathrm{~nm}$. At this wavelength bendamustine shows good absorbance.

Preparation of mobile phase: The mobile phase is composed of a mixture of trifluoroacetic acid and acetonitrile in the ratio of $68: 32(\mathrm{v} / \mathrm{v})$. Prior to use, the mobile phase was degassed and filtered via $0.45 \mu \mathrm{m}$ membrane filter.

Preparation of Buffer: Add $1.0 \mathrm{~mL}$ of Trifluoroacetic acid in $1000 \mathrm{~mL}$ water, sonicate for 10 minutes and filter using $0.45 \mu$ filters.

\section{Chromatographic Conditions}

\begin{tabular}{|c|c|}
\hline Instrument & $\begin{array}{c}\text { Shimadzu LC 20 10 CHT pump, } \\
\text { PDA Detector }\end{array}$ \\
\hline Injection Volume & $10 \mu \mathrm{l}$ \\
\hline Mobile Phase & $\begin{array}{c}\text { Trifluoroacetic acid : Acetonitrile } \\
(68: 32)\end{array}$ \\
\hline Column & $\begin{array}{c}\text { Inertsil ODS }-2,(150 \times 4.6) \mathrm{mm}, \\
5 \mu \mathrm{m}\end{array}$ \\
\hline Wavelength & $230 \mathrm{~nm}$ \\
\hline Flow Rate & $1.5 \mathrm{ml} / \mathrm{mim}$ \\
\hline Runtime & $10 \mathrm{~min}$ \\
\hline
\end{tabular}

Table 3: Variables in HPLC.

\section{Validation of Rp-Hplc Method}

Validation is a key process for effective quality assurance. "Validation" is established documented evidence, which provides a high degree of assurance that a specific process or equipment will consistently produce a product or result meeting its predetermined specification and quality attributes. The Validation parameters are:

- Specificity

- Linearity

- System Suitability Parameters

- Precision

- Accuracy or Recovery

- Assay

- Ruggedness

- Robustness

- LOD and LOQ

Specificity: Specificity is the ability to measure accurately and specifically the analyte in the presence of components that may be expected to be present in the sample. It is the measure of degree of interference (or absence thereof) in the complex sample mixtures such as the analyte mixed with the formulation excipients, known impurities and degradation product.

Linearity: The linearity of an analytical procedure is its ability to obtain test results which are directly proportional to the concentration of analyte in sample.

System suitability: The System suitability is an integral part of analytical procedure. The tests are based on the concept that the equipment, analytical operations and samples to be analyzed constitute an integral system that can be evaluated as such. 
Precision: Precision is the degree of closeness of agreement among individual test results when the method is applied to multiple samplings of a homogenous sample. It is a measure of either the degree of reproducibility (agreement under different conditions) or repeatability (agreement under same conditions) of the method.

Ruggedness: Ruggedness is the degree of reproducibility of the results obtained under a variety of conditions.

Robustness: The robustness of an analytical procedure is a measure of its capacity to remain unaffected by small, but deliberate variations in method parameters and provides an indication of its reliability during normal usage. Robustness study is performed by analyzing the standard at different conditions. The results obtained with altered conditions are compared against results obtained under normal chromatographic conditions.

Variation in Flow Rate $( \pm 0.2 \mathrm{~mL} / \mathrm{min})$ : The standard was carried out by varying the flow rate of mobile phase to $1.3 \mathrm{~mL} / \mathrm{min}$. and $1.7 \mathrm{~mL} / \mathrm{min}$. in place of actual flow rate $1.5 \mathrm{~mL} / \mathrm{min}$.

Variation in Column Oven Temperature $\left( \pm 2^{\circ} \mathrm{C}\right)$ : The standard was carried out by varying the column oven temperature of $23^{\circ} \mathrm{C}$ and $27^{\circ} \mathrm{C}$ in place of actual column oven temperature $25^{\circ} \mathrm{C}$.

Variation in Organic composition ( $\pm 2 \%$ of absolute): The standard was carried out by varying the mobile phase organic composition of 68:32 and 72:28 in place of actual Mobile phase organic composition 70:30.

Accuracy: The accuracy of an analytical procedure expresses the closeness of agreement between the value that is accepted either as a conventional true value or an accepted reference value and the value found. To demonstrate the accuracy of assay test method, drug substance is spiked quantitatively in to placebo from $50 \%$ to $150 \%$ of working concentration of test concentration at each level with triplicate preparation and analyzed using the test method. Typical chromatogram of Accuracy at $100 \%$ level for is shown in figure 4 .

\section{Results and Discussion}

\section{Selection of Chromatographic Method}

Proper selection of the method depends on the nature of the sample (ionic or ionisable or neutral molecules), its molecular weight, pka value and stability. The drug selected in the present study is polar and so reversed phase or ion exchange chromatography can be used. The reversed phase HPLC was selected for the initial separation because of its simplicity and suitability. From the literature survey and with the knowledge of properties of the selected drug, ODS column was tried. ODS $150 \times 4.5 \mathrm{~mm} 5 \mu$ column was chosen as stationary phase and mobile phase with different compositions such as methanol and water was used. The separations were not observed, so the combination of buffer and methanol was finalized. The buffer used was trifluoroacetic acid buffer.

\section{Effect of Ratio of Mobile Phase}

Under the chromatographic conditions mentioned above, the different ratios of buffer and acetonitrile were tried i.e. for trifluoroacetic acid buffer and acetonitrile 68:32 ratios were tried at which they gave good peaks and minimum retention time and good chromatogram with proper resolution.

\section{System Suitability}

\begin{tabular}{|c|c|c|}
\hline \multirow{2}{*}{ Injection \# } & \multicolumn{2}{|c|}{ Bendamustine Peak } \\
\cline { 2 - 3 } & Retention Time & Area \\
\hline 1 & 4.734 & 1439882 \\
\hline 2 & 4.730 & 1420316 \\
\hline 3 & 4.729 & 1426127 \\
\hline 4 & 4.726 & 1427917 \\
\hline 5 & 4.726 & 1418839 \\
\hline Mean & \multicolumn{2}{|c|}{1.2} \\
\hline \% RSD & \multicolumn{2}{|c|}{5299} \\
\hline Tailing factor & \\
\hline Theoretical Plate & \\
\hline
\end{tabular}

Table 4: Results of system suitability for bendamustine

\section{Acceptance Criteria}

$>$ The Tailing factor for Bendamustine peak from first injection of standard solution should be not more than 2.0 .

$>$ Theoretical Plates for Bendamustine peak from first injection of standard solution should be not less than 2000.

$>$ The relative standard deviation for Bendamustine peak from five replicate injections of standard solution should be not more than $2.0 \%$.

Conclusion: The results met the acceptance criteria; hence the method is system suitable for its intended use.

Linearity: The linearity of an analytical procedure is its ability to obtain test results which are directly 
proportional to the concentration of analyte in sample. The linearity of Bendamustine Hydrochloride is established by analyzing Linearity solutions of different concentrations from $10 \%$ to $150 \%$ of working concentration of method for Assay. The Linearity curve is plotted for area versus concentration. The results are summarized in table 5. Typical chromatogram of Linearity at $100 \%$ level is shown in figure1. The linearity graph of is shown in figure 1 . Typical chromatogram of Linearity at $100 \%$ level is shown in figure 2 .

\begin{tabular}{|c|c|c|}
\hline Linearity Level & Bendamustine HCl $(\boldsymbol{\mu g} / \mathbf{m L})$ & Area \\
\hline $10 \%$ & 5 & 142361 \\
\hline $20 \%$ & 10 & 286356 \\
\hline $50 \%$ & 25 & 711354 \\
\hline $80 \%$ & 40 & 1137043 \\
\hline $90 \%$ & 45 & 1281833 \\
\hline $100 \%$ & 50 & 1426716 \\
\hline $125 \%$ & 63 & 1751978 \\
\hline $150 \%$ & 75 & 2111795 \\
\hline \multicolumn{2}{|c|}{ Correlation coefficient (R) :0.9999 } & Y-intercept: 7930.9 \\
\hline \multicolumn{2}{|c|}{ Slope : 27800} & $\begin{array}{c}\text { Y-intercept bias at } 100 \% \\
\text { level :0.6 }\end{array}$ \\
\hline
\end{tabular}

Table 5: Results for linearity of bendamustine.

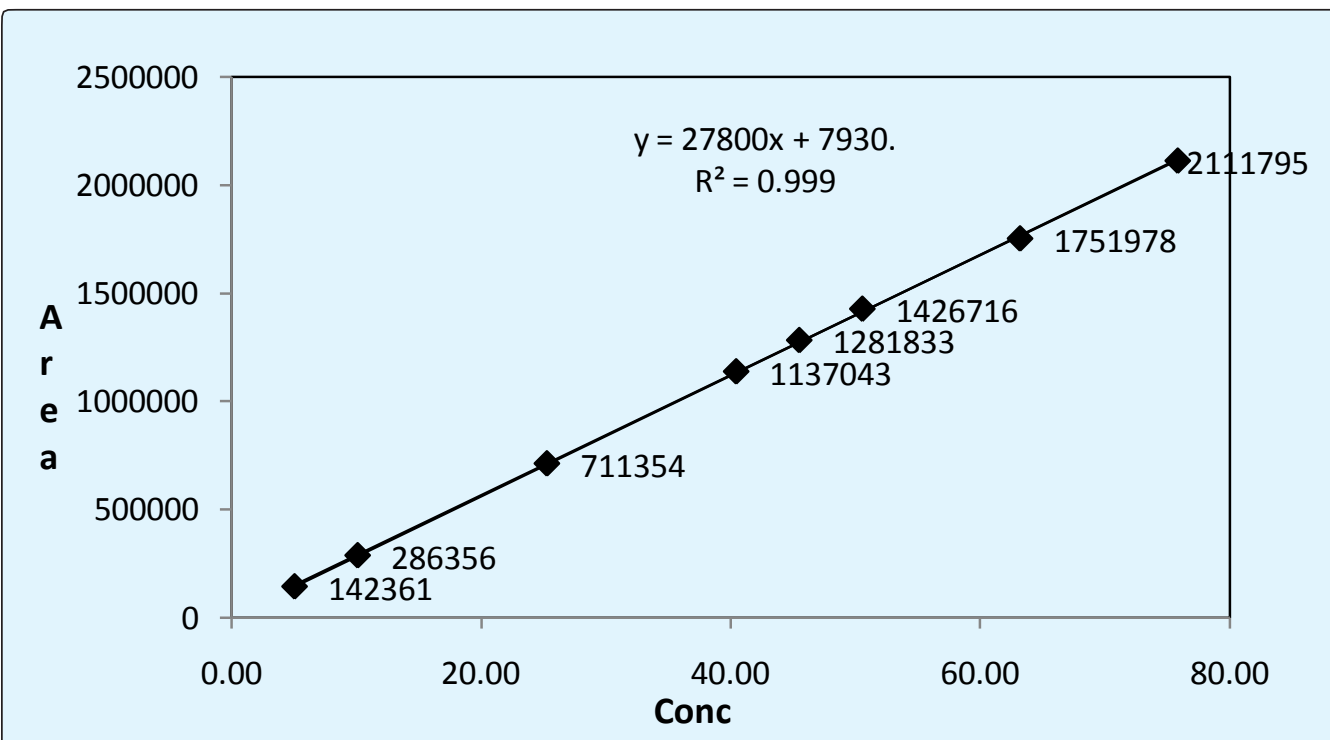

Figure 1: Linearity Graph of Bendamustine $\mathrm{HCl}$.

\section{Acceptance Criteria:}

$>$ Correlation coefficient should not be less than 0.999 for Bendamustine Hydrochloride.

Report the slope of regression line.

Report the Y-intercept of regression line.

Y-intercept bias at $100 \%$ level should be between \pm 5.0 $\%$ for Bendamustine Hydrochloride.

\section{Conclusion}

The results are within the acceptance criteria; hence the analytical procedure is linear within the concentration range from $10 \%$ to $150 \%(5.057 \mu \mathrm{g} / \mathrm{mL}$ to $75.849 \mu \mathrm{g} / \mathrm{mL})$ for Bendamustine Hydrochloride. 


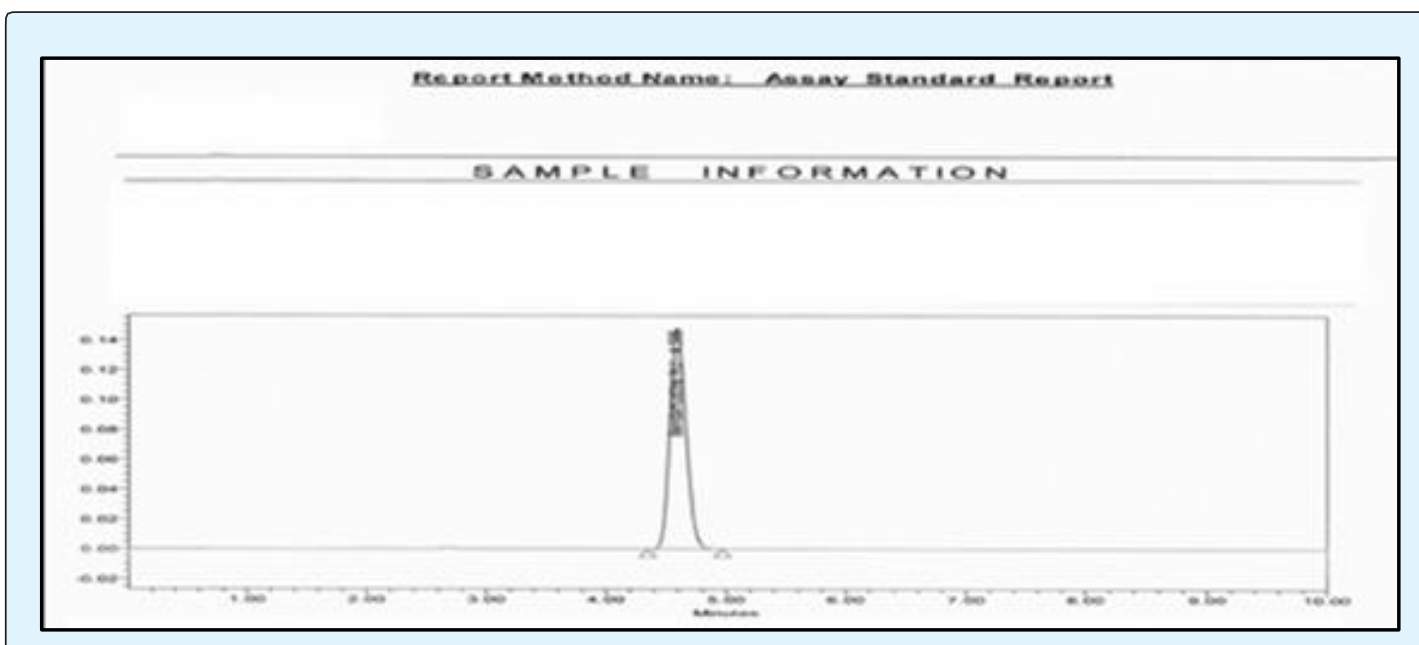

Figure 2: Typical chromatogram of linearity.

\section{Precision}

\begin{tabular}{|c|c|c|}
\hline Sample \# & Retention Time (Average) & \% Assay \\
\hline 1 & 4.163 & 101.0 \\
\hline 2 & 4.170 & 100.5 \\
\hline 3 & 4.174 & 100.5 \\
\hline 4 & 4.171 & 101.6 \\
\hline 5 & 4.174 & 101.8 \\
\hline 6 & 4.179 & 101.6 \\
\hline Mean & & 101.2 \\
\hline \% RSD & & 0.6 \\
\hline
\end{tabular}

Table 6: Results of Intermediate Precision.

\section{Acceptance Criteria:}

$>$ The relative standard deviation of results obtained from six sample preparations should not be more than $2.0 \%$
Conclusion: The result meets the acceptance criteria and found comparable, indicates that the method is precise.

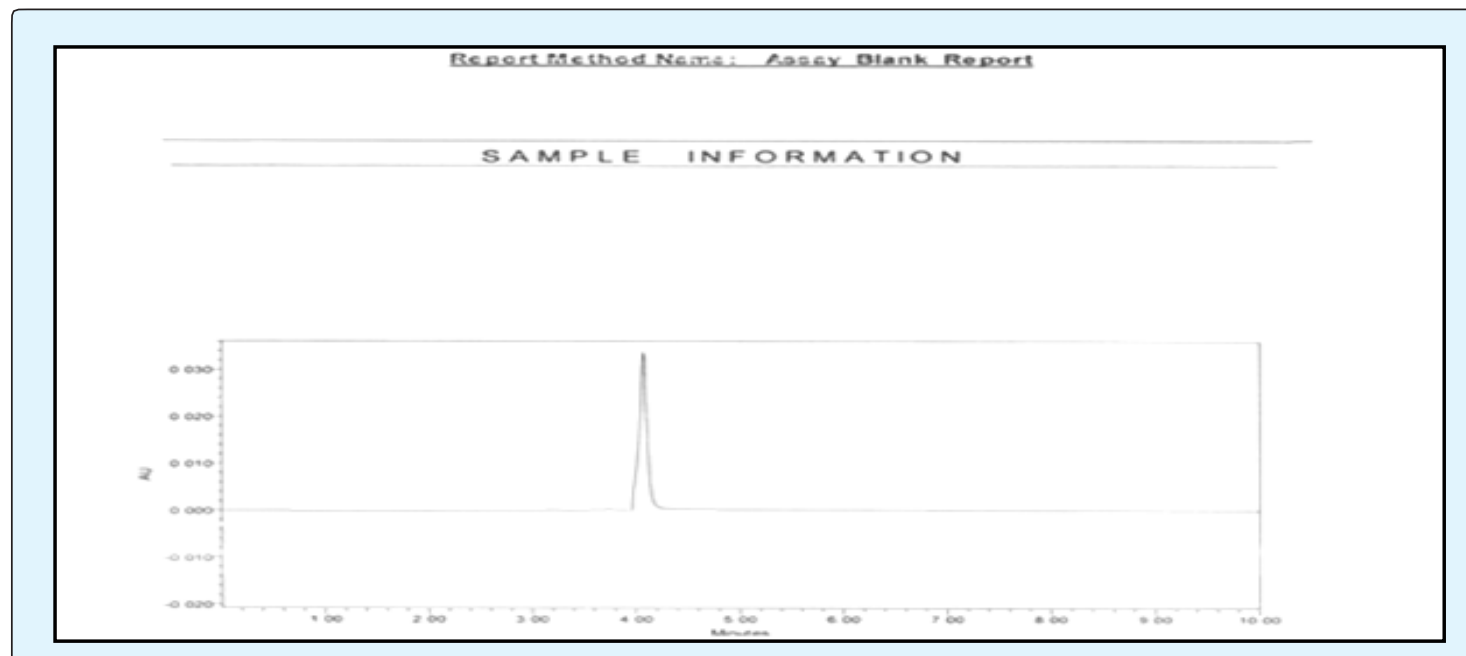

Figure 3: Chromatogram of Precision. 
Open Access Journal of Pharmaceutical Research

\begin{tabular}{|c|c|c|c|c|c|c|}
\hline Accuracy Leve & Sample \# & $\begin{array}{c}\text { Amount } \\
\text { (mg added) }\end{array}$ & $\begin{array}{c}\text { Amount } \\
\text { (mg found) }\end{array}$ & \% Recovery & $\begin{array}{c}\text { Average } \\
\text { \% Recovery }\end{array}$ & $\%$ RSD \\
\hline \multirow{3}{*}{$50 \%$} & 1 & 47.235 & 47.515 & 100.6 & \multirow{3}{*}{100.5} & \multirow{3}{*}{0.1} \\
\hline & 2 & 47.329 & 47.578 & 100.5 & & \\
\hline & 3 & 47.207 & 47.399 & 100.4 & & \\
\hline \multirow{3}{*}{$100 \%$} & 1 & 94.479 & 94.468 & 100.0 & \multirow{3}{*}{99.4} & \multirow{3}{*}{0.9} \\
\hline & 2 & 94.329 & 94.114 & 99.8 & & \\
\hline & 3 & 94.404 & 92.880 & 98.4 & & \\
\hline \multirow{3}{*}{$150 \%$} & 1 & 141.367 & 139.762 & 98.9 & \multirow{3}{*}{99.1} & \multirow{3}{*}{0.3} \\
\hline & 2 & 141.432 & 140.186 & 99.1 & & \\
\hline & 3 & 141.301 & 140.407 & 99.4 & & \\
\hline \multicolumn{6}{|c|}{ \% Recovery for 9 levels } & 99.7 \\
\hline \multicolumn{6}{|c|}{$\%$ RSD for 9 levels } & 0.8 \\
\hline
\end{tabular}

Table 7: Results for accuracy of bendamustine.

Accuracy (Recovery): To demonstrate the accuracy of assay test method, drug substance is spiked quantitatively in to placebo from $50 \%$ to $150 \%$ of working concentration of test concentration at each level with triplicate preparation and analyzed using the test method. The result for Bendamustine $\mathrm{HCl}$ is tabulated in Table 7. Typical chromatogram of Accuracy at $100 \%$ level for is exhibited in figure 4.

\section{Acceptance Criteria:}

$>\%$ Recovery at each level and overall \% recovery should be between 98.0 and 102.0 for Bendamustine $\mathrm{HCl}$.

The \% RSD at each level and overall recovery should not be more than 2.0.

Conclusion: The results are well within the acceptance criteria; hence the method is accurate for its intended use.

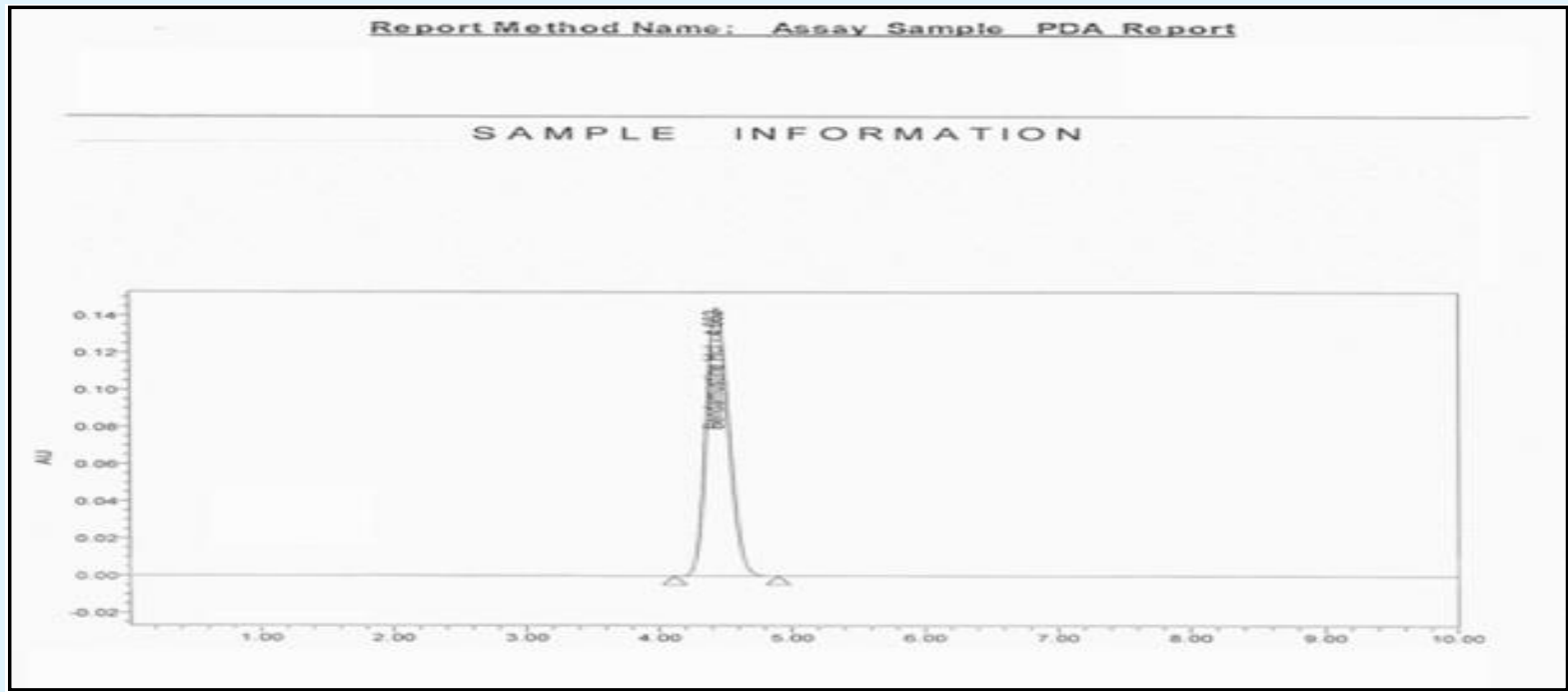

Figure 4: Typical Chromatogram for Accuracy.

\section{Specificity}

Specificity is the ability of the analytical procedure to assess unequivocally the analyte in the presence of components which may be expected to be present. 


\section{Open Access Journal of Pharmaceutical Research}

\begin{tabular}{|c|c|c|}
\hline Name & Retention time (min.) & Results \\
\hline Diluent & No Peak detected & No interference observed \\
\hline Placebo 25mg per vial & No Peak detected & No interference observed \\
\hline Placebo 100mg per vial & No Peak detected & No interference observed \\
\hline Bendamustine Hydrochloride in Standard solution & 4.595 & N/A \\
\hline $\begin{array}{c}\text { Bendamustine Hydrochloride in Sample solution } \\
\text { 25mg per vial }\end{array}$ & 4.670 & N/A \\
\hline $\begin{array}{c}\text { Bendamustine Hydrochloride in Sample solution } \\
\text { 100mg per vial }\end{array}$ & 4.664 & NA \\
\hline $\begin{array}{c}\text { Bendamustine Hydrochloride in Spiked sample } \\
\text { solution }\end{array}$ & 4.662 & \\
\hline
\end{tabular}

Table 8: Specificity Results for bendamustine.

\section{Acceptance Criteria:}

$>$ There should be no interference at the retention time of Bendamustine peak in the Chromatograms obtained from the diluent and the placebo solutions.

\section{Conclusion:}

No Interference is observed at the retention time of Bendamustine peak in the chromatograms obtained from the diluent, placebo. The results met the acceptance criteria; hence the method is specific for its intended use.

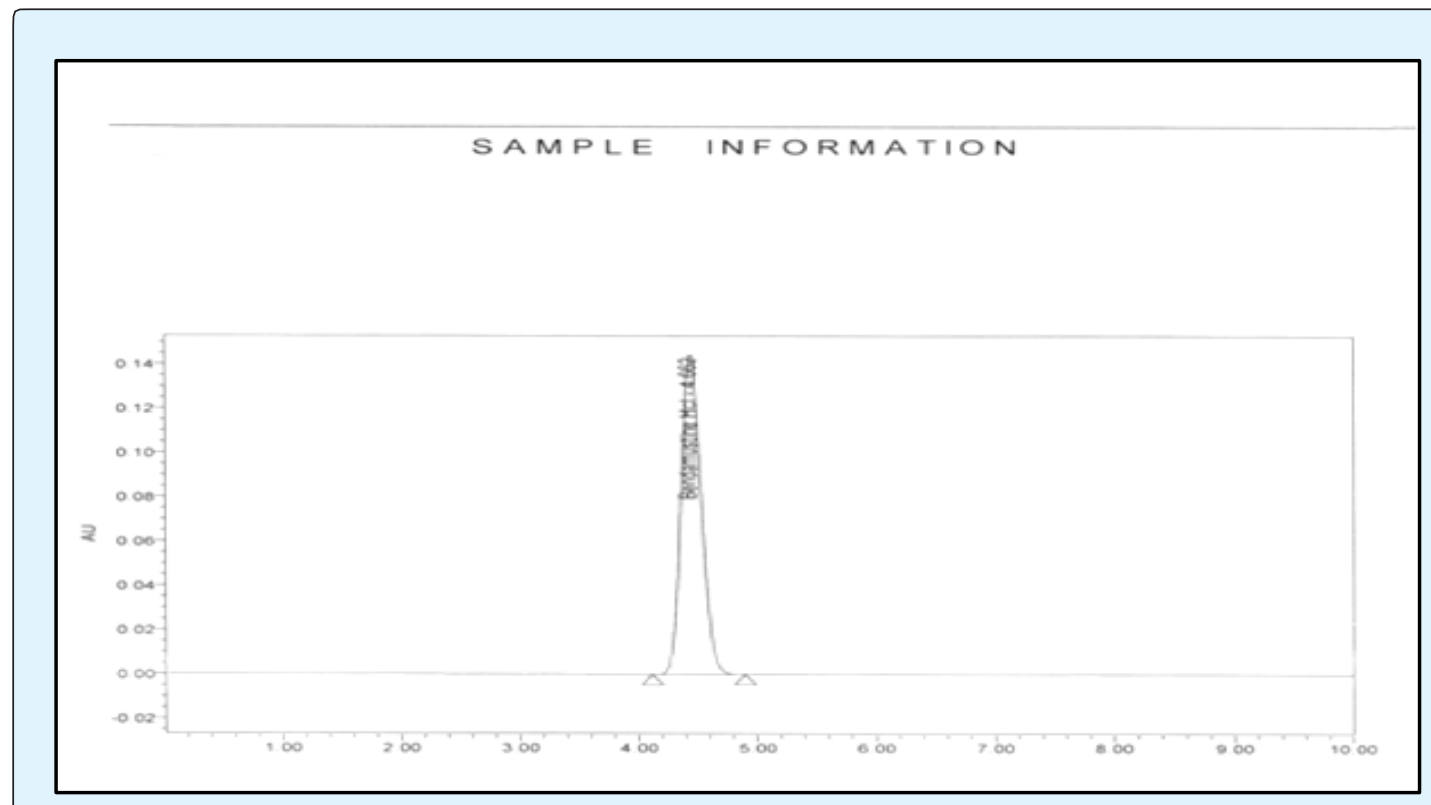

Figure 5: Typical chromatogram for specificity.

\section{Ruggedness}

Ruggedness is the degree of reproducibility of the results obtained under a variety of conditions. It was checked that the results were reproducible under differences in conditions, analysts and instruments.

Procedure: The standard solution and sample solution

\begin{tabular}{|c|c|c|}
\hline Injection & Analyst 1 & Analyst 2 \\
\hline $\mathrm{Rt}$ & 4.734 & 4.731 \\
\hline Peak Area & 1439882 & 1426127 \\
\hline
\end{tabular}

Table 9: Results for ruggedness of bendamustine. were injected by different analysts and the area for injections in HPLC was measured. 




Figure 6: Typical chromatogram for Ruggedness.

\section{Robustness}

The robustness of an analytical procedure is a measure of its capacity to remain unaffected by small, but deliberate variations in method parameters and provides an indication of its reliability during normal usage. Robustness study is performed by analyzing the standard at different conditions. The results obtained with altered conditions are compared against results obtained under normal chromatographic conditions.

Variation in Flow Rate $( \pm 0.2 \mathrm{~mL} / \mathrm{min}$.): The standard was carried out by varying the flow rate of mobile phase to $1.3 \mathrm{~mL} / \mathrm{min}$. and $1.7 \mathrm{~mL} / \mathrm{min}$. in place of actual flow rate $1.5 \mathrm{~mL} / \mathrm{min}$. The results are summarized in Table 10 .

\begin{tabular}{|c|c|c|c|c|c|c|}
\hline \multirow{2}{*}{ Injection \# } & \multicolumn{2}{|c|}{$\begin{array}{c}\text { Flow Rate } \\
1.3 \mathrm{~mL} / \mathrm{min} .\end{array}$} & \multicolumn{2}{|c|}{$\begin{array}{c}\text { Actual Flow Rate } \\
1.5 \mathrm{~mL} / \mathrm{min} .\end{array}$} & \multicolumn{2}{|c|}{$\begin{array}{c}\text { Flow Rate } \\
1.7 \mathrm{~mL} / \mathrm{min} .\end{array}$} \\
\hline & RT & Area & RT & Area & RT & Area \\
\hline 1 & 4.417 & 1604526 & 4.734 & 1439882 & 4.170 & 1245237 \\
\hline 2 & 4.417 & 1608707 & 4.730 & 1420316 & 4.169 & 1243739 \\
\hline 3 & 4.417 & 1610521 & 4.729 & 1426127 & 4.169 & 1245069 \\
\hline 4 & 4.417 & 1601094 & 4.726 & 1418839 & 4.169 & 1249676 \\
\hline 5 & 4.418 & 1608861 & 4.726 & 1427917 & 4.169 & 1242068 \\
\hline Mean & NA & 1606742 & NA & 1426616 & NA & 1245158 \\
\hline$\%$ RSD & NA & 0.2 & NA & 0.6 & NA & 0.2 \\
\hline Tailing factor & \multicolumn{2}{|c|}{$\frac{1}{1.2}$} & \multicolumn{2}{|c|}{1.2} & \multicolumn{2}{|c|}{1.1} \\
\hline Theoretical Plates & \multicolumn{2}{|c|}{5598} & \multicolumn{2}{|c|}{5299} & \multicolumn{2}{|c|}{4842} \\
\hline
\end{tabular}

Table 10: Results of Robustness-Variation in Flow rate for Bendamustine.

Variation in Column Oven Temperature $\left( \pm 2^{\circ} \mathrm{C}\right)$ : The standard was carried out by varying the column oven temperature of $23^{\circ} \mathrm{C}$ and $27^{\circ} \mathrm{C}$ in place of actual column oven temperature $25^{\circ} \mathrm{C}$. The results are summarized. The results are summarized in Table 11 . 


\begin{tabular}{|c|c|c|c|c|c|c|}
\hline \multirow{2}{*}{ Injection \# } & \multicolumn{2}{|c|}{$\begin{array}{c}\text { Column Oven Temperature } \\
23^{\circ} \mathrm{C} \\
\end{array}$} & \multicolumn{2}{|c|}{$\begin{array}{c}\text { Actual Column Oven } \\
\text { Temperature } 25^{\circ} \mathrm{C} \\
\end{array}$} & \multicolumn{2}{|c|}{$\begin{array}{c}\text { Column Oven } \\
\text { Temperature } 27^{\circ} \mathrm{C} \\
\end{array}$} \\
\hline & RT & Area & RT & Area & RT & Area \\
\hline 1 & 4.857 & 1412117 & 4.734 & 1439882 & 4.571 & 1421139 \\
\hline 2 & 4.857 & 1405844 & 4.730 & 1420316 & 4.570 & 1422116 \\
\hline 3 & 4.857 & 1392908 & 4.729 & 1426127 & 4.568 & 1423122 \\
\hline 4 & 4.857 & 1403670 & 4.726 & 1418839 & 4.567 & 1421483 \\
\hline 5 & 4.857 & 1406250 & 4.726 & 1427917 & 4.567 & 1420494 \\
\hline Mean & NA & 1404158 & NA & 1426616 & NA & 1421671 \\
\hline$\%$ RSD & NA & 0.5 & NA & 0.6 & NA & 0.1 \\
\hline Tailing factor & \multicolumn{2}{|c|}{1.2} & \multicolumn{2}{|c|}{1.2} & \multicolumn{2}{|c|}{1.2} \\
\hline Theoretical plate & \multicolumn{2}{|c|}{4999} & \multicolumn{2}{|c|}{5299} & \multicolumn{2}{|c|}{5314} \\
\hline
\end{tabular}

Table 11: Results of Robustness-Variation in Column Oven Temperature for Bendamustine.

Variation in Organic composition $( \pm 2 \%$ of absolute)

The standard was carried out by varying the mobile phase organic composition of $68: 32$ and 72:28 in place of actual
Mobile phase organic composition 70:30. The results are summarized. The results are summarized in Table 12.

\begin{tabular}{|c|c|c|c|c|c|c|}
\hline \multirow{2}{*}{ Injection \# } & \multicolumn{2}{|c|}{$\begin{array}{c}\text { Mobile phase composition } \\
\text { (68:32) }\end{array}$} & \multicolumn{2}{c|}{$\begin{array}{c}\text { Actual Mobile phase } \\
\text { composition (70:30) }\end{array}$} & $\begin{array}{c}\text { Mobile phase composition } \\
\text { (72:28) }\end{array}$ \\
\cline { 2 - 7 } & RT & Area & RT & Area & RT & Area \\
\hline 1 & 4.731 & 1436831 & 4.734 & 1439882 & 4.454 & 1392300 \\
\hline 2 & 4.731 & 1413689 & 4.730 & 1420316 & 4.454 & 1386460 \\
\hline 3 & 4.731 & 1409539 & 4.729 & 1426127 & 4.455 & 1390738 \\
\hline 4 & 4.731 & 1415929 & 4.726 & 1418839 & 4.456 & 1387169 \\
\hline 5 & 4.732 & 1423610 & 4.726 & 1427917 & 4.456 & 1391037 \\
\hline Mean & NA & 1420460 & NA & 1426616 & NA & 1389541 \\
\hline \% RSD & NA & 0.8 & NA & 0.6 & NA & 0.2 \\
\hline Tailing factor & \multicolumn{3}{|c|}{1.2} & \multicolumn{2}{|c|}{5299} & \multicolumn{2}{c|}{4568} \\
\hline Theoretical plates
\end{tabular}

Table 12: Results of Robustness-Variation in organic composition for Bendamustine Hydrochloride.

\section{Acceptance criteria:}

$>$ The Tailing factor for Bendamustine peak from first injection of standard solution should be not more than 2.0 .

> Theoretical Plates for Bendamustine peak from first injection of standard solution should be not less than 2000.

> The relative standard deviation for Bendamustine peak from five replicate injections of standard solution should be not more than $2.0 \%$.

Conclusion: The system suitability meets for each altered conditions. The results obtained with altered conditions are comparable with the results obtained with normal conditions. The robustness result indicates that the test method is robust enough as demonstrated by altering the
Flow rate $\left( \pm 0.2 \mathrm{~mL} / \mathrm{min}\right.$.), column temperature $\left( \pm 0.2^{\circ} \mathrm{C}\right)$ and organic composition ( $\pm 2 \%$ of absolute).

Sensitivity: Limit of Detection (LOD), Limit of Quantification (LOD) was examined by injecting six consecutive injections of bendamustine solutions at lowest concentration $\left(10 \mu \mathrm{g} \mathrm{mL}^{-1}\right)$. LOD can be calculated by using the formula, LOD $=3.3 \times$ S.D/slope. LOQ can be calculated by using the formula, LOD $=10 \times$ S.D/slope.

The obtained LOD and LOQ values were found to be 2.9 $\mu \mathrm{g} / \mathrm{ml}$ and $8.75 \mu \mathrm{g} / \mathrm{ml}$.

\section{Summary and Conclusion}

A simple, sensitive and reproducible HPLC method for determination of bendamustine has been developed in bulk and tablet dosage forms. The validation parameters 


\section{Open Access Journal of Pharmaceutical Research}

were found to be highly agreeable, indicating small sample volume, short retention time, system suitability, specificity, linearity, limits of detection and quantification, precision, accuracy and robustness. Hence, the proposed method can be easily applied for the quantification of bendamustine in routine quality control laboratories.

\section{References}

1. Dubbelman AC, Rosing H, Darwish M, D'Andrea D, Bond M, et al. (2013) Pharmacokinetics and excretion of bendamustine in patients with relapsed or refractory malignancy. Drugs R D 13(1): 17-28.

2. Neil O, Maryadele J (2006) The Merck index: an encyclopedia of chemicals, drugs, and biologicals. Merck Research Laboratories, Whitehouse Station, NJ, Merck.

3. Friedberg JW, Cohen P, Chen L, Sue Robinson K, Forero-Torres A, et al. (2008) Bendamustine in Patients With Rituximab-Refractory Indolent and Transformed Non-Hodgkin's Lymphoma: Results From a Phase II Multicenter, Single-Agent Study. J Clinical Oncology 26(2): 204-210.

4. Lissitchkov T, Arnaudov G, Peytchev D, Merkle KH (2006) Phase-I/II study to evaluate dose limiting toxicity, maximum tolerated dose, and tolerability of bendamustine $\mathrm{HCl}$ in pre-treated patients with $\mathrm{B}$ chronic lymphocytic leukaemia (Binet stages B and C) requiring therapy. Journal of Cancer Research and Clinical Oncology 132(2): 99-104.

5. Teichert J, Sohr R, Baumann F, Hennig L, Merkle K, et al. (2005) Synthesis and characterization of some new phase ii metabolites of the alkylator bendamustine and their identification in human bile, urine, and plasma from patients with cholangiocarcinoma. Drug Metabolism and Disposition 33(7): 984-992.

6. Matt Kalaycio (2008) Clinical Experience with Bendamustine: A new treatment for patients with chronic lymphocytic leukemia. Clinical Leukemia 2(4): 223-229.

7. Teichert J, Baumann F, Qi Chao, Franklin C, Bailey B, et al. (2007) Characterization of two phase I metabolites of bendamustine in human liver microsomes and in cancer patients treated with bendamustine hydrochloride. Cancer Chemotherapy and Pharmacology 59(6): 759-770.

8. Rasschaert M, Schrijvers D, Van den Brande J, Dyck J, Bosmans J, et al. (2007) A phase I study of bendamustine hydrochloride administered day $1+2$ every 3 weeks in patients with solid tumours. British Journal of Cancer 96: 1692-1698.

9. Preiss R, Sohr R, Matthias M, Brockmann B, Huller H (1985) The pharmacokinetics of bendamustine (Cytostasane) in humans. Die Pharmazie 40(11): 782784.

10. Ivanka Pencheva, Anita Bogomilova, Neli Koseva, Danka Obreshkova, Kolio Troev (2008) HPLC study on the stability of bendamustine hydrochloride immobilized onto polyphosphoesters. Journal of Pharmaceutical and Biomedical Analysis 48(4): 11431150.

11. Mathrusri Annapurna M, Pavani S, Anusha S, Harika Mahanti, Venkatesh B (2012) New analytical methods for the determination of Bendamustine hydrochloride: An anti-neoplastic drug. J Chem Pharm Res 4(3): 1696-1701.

12. (2005) ICH Validation of analytical procedures: Text and methodology Q2 (R1). International Conference on Harmonization.

13. (2003) ICH Stability Testing of New Drug Substances and Products Q1A (R2). International Conference on Harmonization.

14. Grever MR, Andritsos LA, Lozanski G (2008) Chronic lymphoid leukemias, Abeloffs Clinical Oncology, Elsevier $4^{\text {th }}$ (Edn.), Philadelphia, pp: 2293-2308.

15. Sasi kiran goud E, Krishna reddy V (2013) Development and validation of RP-HPLC method for determination of related substances of Bendamustine hydrochloride in bulk drug. Der Pharmacia Sin 4(1): 29-36.

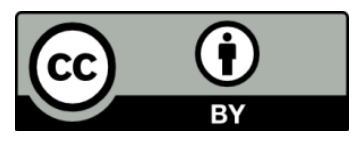

Bhawani S, et al. Analytical Method Development and Validation of Bendamustine in Bulk Using RP-HPLC. Pharm Res 2018, 2(2): 000158. 